\title{
Migraine attacks among medical students in Soochow University, Southeast China: a cross-sectional study
}

This article was published in the following Dove Press journal: Journal of Pain Research

\author{
Xiao $\mathrm{Gu}^{1,2}$ \\ Yaojie Xie' \\ 'School of Nursing, The Hong \\ Kong Polytechnic University, Hong \\ Kong; ${ }^{2}$ Intensive Care Unit, Suzhou \\ Municipal Hospital, Suzhou, China
}

Correspondence: Yaojie Xie FG424, School of Nursing, The Hong Kong Polytechnic University, II Yuk Choi Road, Hung Hom, Kowloon, Hong Kong

Tel +85234003798

Fax +852 23649663

Email grace.yj.xie@polyu.edu.hk

\begin{abstract}
Purpose: Migraine is one of the most common primary headache disorders and is burdensome to both the individual and society, influencing the academic performance and quality of daily lives of medical students worldwide. This study aimed to investigate the migraine prevalence in a sample of university medical students in China and to examine the features and typical trigger factors of migraine among these students.
\end{abstract}

Patients and methods: From May 2016 to August 2016, a total of 1,060 medical students who were enrolled in Soochow University in Jiangsu Province in China were chosen through stratified random sampling. A self-administered questionnaire that included the ID Migraine ${ }^{\mathrm{TM}}$ for screening of migraine cases was used to collect data. The frequency, severity, duration of migraine attacks, and relevant trigger factors were measured for migraine cases. In total, 986 students completed the questionnaire.

Results: The overall migraine prevalence among students was $7.91 \%$, with $4.64 \%$ in male and $9.84 \%$ in female students. Junior-grade students had a higher migraine prevalence than senior students (prevalence of migraine of year 1 to year 5 undergraduates: $10.83 \%, 8.9 \%$ vs. $6.25 \%, 4.42 \%$, $5.33 \%, P<0.05$; prevalence of migraine of year 1 to year 3 graduates: $9.68 \%, 9.71 \%$ vs. $6.38 \%$, $P<0.05)$. Students with a positive family history were more likely to suffer migraine than those without (OR=8.48, 95\% CI: 4.33-16.59). Stress ( $n=73,93.59 \%)$, lack of sleep $(n=72,92.31 \%)$, and change of sleeping time $(\mathrm{n}=68,87.18 \%)$ were the top three trigger factors among the students. Conclusion: Migraine was common among medical students from a university in China, and especially higher in female and junior-grade students, and those with a family history of migraine. Reducing stress and improving sleep quality might be effective to reduce migraine attacks in this population.

Keywords: headache, screening, characteristics, gender, family history, junior students, stress, sleep problems

\section{Introduction}

Migraine is among the most common primary headache disorders. The worldwide 1 -year migraine prevalence ranges from $2.6 \%$ to $21.7 \%$, with the prevalence in women being twice or thrice higher than in men. ${ }^{1}$ Migraine is usually nonfatal, but disabling. According to the global burden of disease survey in 2010, migraine was the third most common condition, and led to the seventh highest years lived with disability (YLDs) among ictal disabilities. ${ }^{2,3}$ Migraine causes financial burden to both the individual and society, including direct, such as medical expenses, and indirect, such as work absenteeism and reduced productivity and costs. ${ }^{4}$ 
Most migraine onsets appear during late adolescence to early 30 s; moreover, for the university students who are mostly in their 20 s, the headache attacks are significantly related to increased discipline failures and absenteeism.-8 Other than academic failure, avoiding extra-curricular activities with family and friends greatly influence the quality of daily lives of students. ${ }^{9}$ Medical students are understood to be a special group of university students and, understandably, the prolonged medical education, heavy study load, and demanding professional responsibility are the typical sources of stress that may lead to migraine attacks. ${ }^{9-11}$ Moreover, the work shifts during residency lead to irregular sleeping and dietary habits, which are common triggers of migraine. Thus, studies have been done in many countries to estimate the situation of migraine attacks among medical students. The migraine prevalence varied from $2.4 \%$ to $48.5 \%$ worldwide in this population; ${ }^{12}$ however, the different diagnostic criteria, male to female ratio, and other details of the study methodology may have caused heterogeneity. ${ }^{1}$

Sleep disturbance and study-related stress might be the common trigger factors in medical students; moreover, other triggers, such as weather and climate, missing a meal, loud noises, and menstrual periods, were reported from university students. ${ }^{6,9,11}$ Moreover, inherited traits, different cultural backgrounds, lifestyles, and external environment might cause the diversity of trigger factors; thus, more studies are needed. ${ }^{6,9,11}$

In China, the first national survey for primary headache was conducted from 2008 to 2009, with the migraine prevalence at $9.3 \%{ }^{13}$ However, the study of the prevalence of migraine, features, and trigger factors among medical students was limited. Only one study, conducted in Harbin in Heilongjiang Province, investigated the migraine prevalence and awareness among medical students. ${ }^{14}$ However, the relevant trigger factors remain unknown to Chinese medical students.

In view of this, our study aims to: 1) investigate the migraine prevalence among medical students in Soochow University in Southeast China; and 2) examine the migraine features and determine the common trigger factors in this population.

\section{Material and methods}

\section{Study design and setting}

A cross-sectional study was conducted from May 2016 to August 2016 on medical students in Soochow University in Jiangsu Province in China.

\section{Ethics statement}

This study was approved by the Human Subjects Ethics Sub-committee of The Hong Kong Polytechnic University (HSEARS20160509001) and the Ethics Committee of Soochow University (ECSU-20160006). All participants gave written informed consent. This study was anonymous, voluntary, confidential, beneficial, and harmless. Participants were given the choice to quit the study at any time and without any reason.

\section{Study populations}

The undergraduate and graduate medical students from the Faculty of Medicine of Soochow University comprised the target populations. The inclusion criteria were medical students with majors in clinical medicine, basic medicine and biological sciences, nursing, public health, pharmacy, and radiology, and aged 18 years or above. Those excluded were students studying for continuing education or a higher diploma, or double degree students with non-medical majors. Based on the estimated prevalence of $15 \%$, which was pooled from 35 studies among medical students, ${ }^{12}$ a sample size of 784 was needed to achieve a 0.05 interval width and a $95 \%$ confidence level. Considering the $90 \%$ response rate, the final sample size was 872 . The proportion of undergraduate and graduate medical students in Soochow University was 5,010:2,492; therefore, 582 undergraduate students and 290 graduate students were recruited.

Stratified random sampling according to grade was adopted as the first step in the sampling procedure. The university provided the list of classes and students' IDs. The number of needed participants from each grade was determined by the proportion of students among grades. In each grade, for the undergraduate students, several classes were randomly selected, and all students in those classes were considered potential participants. The graduate students had no unified classes; therefore, individual students were randomly selected from each grade. Invitation emails and phone calls were sent to the corresponding students according to the sampling results.

\section{Data collection Questionnaire}

A self-administered questionnaire was designed to collect data. The questionnaire contained four parts. The first part collected demographical information, including grade, major, age, gender, ethnicity, birthplace, height and weight, living expenses per month, and family history of migraine. 
The second part was the ID Migraine ${ }^{\mathrm{TM}}$ (Pfizer Inc., New York, NY, USA) screening test, which contains a prescreening question (Did you have two or more headaches in the past 3 months?) and a three-item questionnaire based on migraine symptoms. A participant who replies "yes" to the first question and admits to have experienced at least two of the following symptoms (nausea, photophobia, and disability) is considered to have migraine. ID Migraine ${ }^{\mathrm{TM}}$, a brief and efficient tool, is considered useful for diagnosing migraine in primary care settings; moreover, it has been indicated as a successful screening tool in many studies. ${ }^{11,14,16,17}$ The diagnostic accuracy of ID Migraine ${ }^{\mathrm{TM}}$ was quantified in previous studies, and it has a sensitivity of 0.84 (95\% CI, 0.75-0.90) and specificity of 0.76 (95\% CI, 0.69-0.83). ${ }^{15}$ The Chinese version of ID Migraine ${ }^{\mathrm{TM}}$ showed a sensitivity and specificity of $84 \%$ and $64 \%$, respectively, when tested recently. ${ }^{18}$

The third part of the questionnaire involved the assessment of migraine features, including onset time, frequency, duration, and intensity of migraine attacks. The Numerical Rating Scale is widely used for assessing pain intensity in clinical practice, and we adopted it in this questionnaire. Participants evaluated the degree of their headaches on a scale of $0-10$, with 0 being no pain at all and 10 being the worst pain. Students' clinic-visit histories and relief methods for migraine attacks were included in this part of the survey. Except for medications taken, four types of pain relief methods, namely, sleep or rest, water or food intake, hot shower or bath, acupuncture or massage, were listed for selection. The fourth part of the questionnaire listed the potential trigger factors in a Likert-type form. It was mainly based on Mukadder Mollaoglu's List of Trigger Factors of Migraine, ${ }^{19}$ with 12 additional triggers from a clinical study in China. ${ }^{20}$ The part regarding stress was based on a stressor survey among university students in China. ${ }^{21}$ "Bingeing" was added in the dietary factors, following a diet behavior survey among colleges in Suzhou. ${ }^{22}$ In total, 26 trigger factors were listed and subsequently categorized into five aspects, namely, diet (hunger, fasting, bingeing, and consumption of milk and cheese, chocolate, alcohol, coffee, tea, and other foods); sleep (oversleep, lack of sleep, and changes in time of sleep); stress (stress at study or work, personal life, sudden negative incidents, and family); physical activity (exercise and head and neck movements); environmental factors (clarity, changes in temperature, seasonal changes, wind, smoking, smell, and noise); as well as one factor pertaining to women alone - menstrual cycle. The 5-point Likert scale was used to measure the frequency of the trigger factors: 0 -never, 1-rarely/occasionally, 2-sometimes, 3-often, and 4-very often. We then categorized the answers as No (selected " 0 "), Occasional (selected "1" or "2"), and Frequent (selected "3" or "4") for analysis.

Six specialists from neurological departments of three hospitals were invited to assess the content validity of parts three and four of the questionnaire. One item in the trigger factors - "exercises" - was removed because of low itemcontent validity index. A total of 74 students in a class were enrolled to conduct the test-retest reliability test, with a time interval of 2 weeks. Students also suggested adding an option of "irregular" to migraine frequency, describing infrequent attacks of less than once a month for most of the time but extra attacks during some periods. The intra-class correlation coefficient was used to assess the test-retest reliability of this questionnaire, and the reliability of parts three and four were 0.758 and 0.992 , respectively.

\section{Data collection procedure}

A school staff member helped the investigator contact the class monitors and student assistants. For undergraduate students, survey schedules were arranged according to the available time and place provided by the class monitors. The class monitors helped the investigator enter classrooms and deliver questionnaires. Information about the study, such as its purpose, the procedures, and importance, were introduced first and questions from students were answered by the investigator. The students signed the informed consent before answering the questionnaire. To reduce missing or incorrect content, each questionnaire was quickly checked upon submission to the investigator. For graduate students, participants filled the questionnaires in libraries, laboratories, or hospitals during individual visits by the investigator after email or telephone confirmation. Some of the students refused or did not respond to our emails and phone calls. To achieve the expected sample size, we gave the questionnaires to the next student on the list when a student refused to participate.

\section{Data analysis}

The SPSS Statistics version 23 (IBM Corporation, Armonk, NY, USA) was used for data analysis. Continuous variables with normal distributions were described as the mean and SD. Non-normal distributions of continuous data were presented as medians and IQRs. Categorical variables were described as numbers and percentages. Individual sample Student's $t$-test and ANOVA were used to compare the group differences for normally distributed continuous data. Non-normally distributed continuous data were compared using the Mann-Whitney $U$ test. The Chi-square and Fisher's exact tests were used 
for categorical data wherever appropriate. Binary logistic regression analysis was adopted to identify the factors associated with migraine status. Differences between groups were considered significant when $P$ was less than 0.05 .

\section{Results}

A total of 15 classes with 736 undergraduate and 324 graduate students were invited to answer the questionnaire. A total of six undergraduate and 34 graduate students provided no response. The overall response rate was $96.23 \%$, with $99.18 \%$ from undergraduate and $89.51 \%$ from graduate students. In total, 1,020 medical students completed the questionnaires, and 986 valid questionnaires were analyzed.

\section{Characteristics of the participants}

The age of the participants ranged from 18 to 35 years, with a mean age of $22.42 \pm 2.98$ years. The mean body mass index (BMI) was $20.99 \pm 2.71 \mathrm{~kg} / \mathrm{m}^{2}$.

Nearly two thirds (63\%) of the participants were female, which was similar to the overall gender proportion of medical students in Soochow University. Moreover, nearly half of the students lived in urban areas (47\%). Most of the participants (95\%) were of Han nationality. Nearly half (49\%) received
$¥ 800$ —1,200 for living expenses monthly from their respective families, whereas $13 \%$ of students received less than $¥ 800$ monthly. Less than one tenth ( $8.8 \%$ ) of the participants reported a positive family history of migraine, whereas one fifth $(21.1 \%)$ were unaware.

Table 1 shows differences in the demographic characteristics of participants according to gender. More female students were seen in undergraduate students, minority groups, and those from rural areas. Male students were older, with higher BMI and living expenses, and had a low family history of migraine. All these differences were statistically significant.

\section{Prevalence of migraine}

A total of 155 students had two or more headaches in the past 3 months, and 78 were confirmed as having migraine by the ID Migraine ${ }^{\mathrm{TM}}$ screening test. The overall migraine prevalence was 7.91\% (78/986; 95\% CI: 6.23\%-9.60\%); moreover, migraine was slightly more prevalent in graduate students than in undergraduate ones $(8.62 \%$ vs. $7.61 \%)$. Figure 1 shows the migraine prevalence according to study grade. Year 1 and 2 students had higher migraine prevalence than senior students $(P=0.018)$. Table 2 shows the migraine prevalence among different groups of students. Gender, living expenses,

Table I Demographic characteristics of participants according to gender

\begin{tabular}{|c|c|c|c|c|}
\hline Characteristics & Total $(\mathbf{N}=986)$ & Male $(n=366)$ & Female $(n=620)$ & $\mathbf{P}$ \\
\hline Education level & & & & 0.000 \\
\hline Undergraduate & $696(70.6 \%)$ & $227(62.0 \%)$ & 469 (75.6\%) & \\
\hline Graduate & $290(29.4 \%)$ & $139(38.0 \%)$ & I5I (24.4\%) & \\
\hline Grade & & & & 0.554 \\
\hline Grade I & $250(25.4 \%)$ & $83(22.7 \%)$ & 167 (26.9\%) & \\
\hline Grade 2 & $294(29.8 \%)$ & $110(30.1 \%)$ & $184(29.7 \%)$ & \\
\hline Grade 3 & $254(25.8 \%)$ & $103(28.1 \%)$ & I5I (24.4\%) & \\
\hline Grade 4 & $113(11.5 \%)$ & 43 (II.7\%) & 70 (II.3\%) & \\
\hline Grade 5 & 75 (7.6\%) & $27(7.4 \%)$ & 48 (7.7\%) & \\
\hline Ethnicity & & & & 0.021 \\
\hline Han & 939 (95.2\%) & $356(97.3 \%)$ & $583(94.0 \%)$ & \\
\hline Minority & 47 (4.8\%) & $10(2.7 \%)$ & 37 (6.0\%) & \\
\hline Birthplace & & & & 0.001 \\
\hline Rural & $523(53.0 \%)$ & I 68 (45.9\%) & 355 (57.3\%) & \\
\hline Urban & $463(47.0 \%)$ & 198 (54.1\%) & 265 (42.7\%) & \\
\hline Living expenses/per month & & & & 0.033 \\
\hline$\leq ¥ 800$ & 127 (12.9\%) & $40(10.9 \%)$ & $87(14.0 \%)$ & \\
\hline$¥ 800-1,200$ & 486 (49.3\%) & 169 (46.2\%) & $317(51.5 \%)$ & \\
\hline$\geq ¥ 1,200$ & $373(37.8 \%)$ & 157 (42.9\%) & $216(34.8 \%)$ & \\
\hline Family history of migraine & & & & 0.031 \\
\hline Yes & 87 (8.8\%) & 30 (8.2\%) & 57 (9.2\%) & \\
\hline No & 691 (70.1\%) & 274 (74.9\%) & $417(67.3 \%)$ & \\
\hline Unknown & $208(21.1 \%)$ & $62(16.9 \%)$ & $146(23.5 \%)$ & \\
\hline Age, years & $22.4(3.0)$ & $23.1(3.2)$ & $22.0(2.7)$ & 0.000 \\
\hline Body mass index, $\mathrm{kg} / \mathrm{m}^{2}$ & $20.8(2.6)$ & $22.1(1.4)$ & $20.0(2.1)$ & 0.000 \\
\hline
\end{tabular}

Notes: Values reported as mean (SD) or $\mathrm{n}(\%)$ for total sample and for each gender group where appropriate. P-values generated from one-way ANOVA or Pearson Chisquare test or Fisher's exact test where appropriate. 


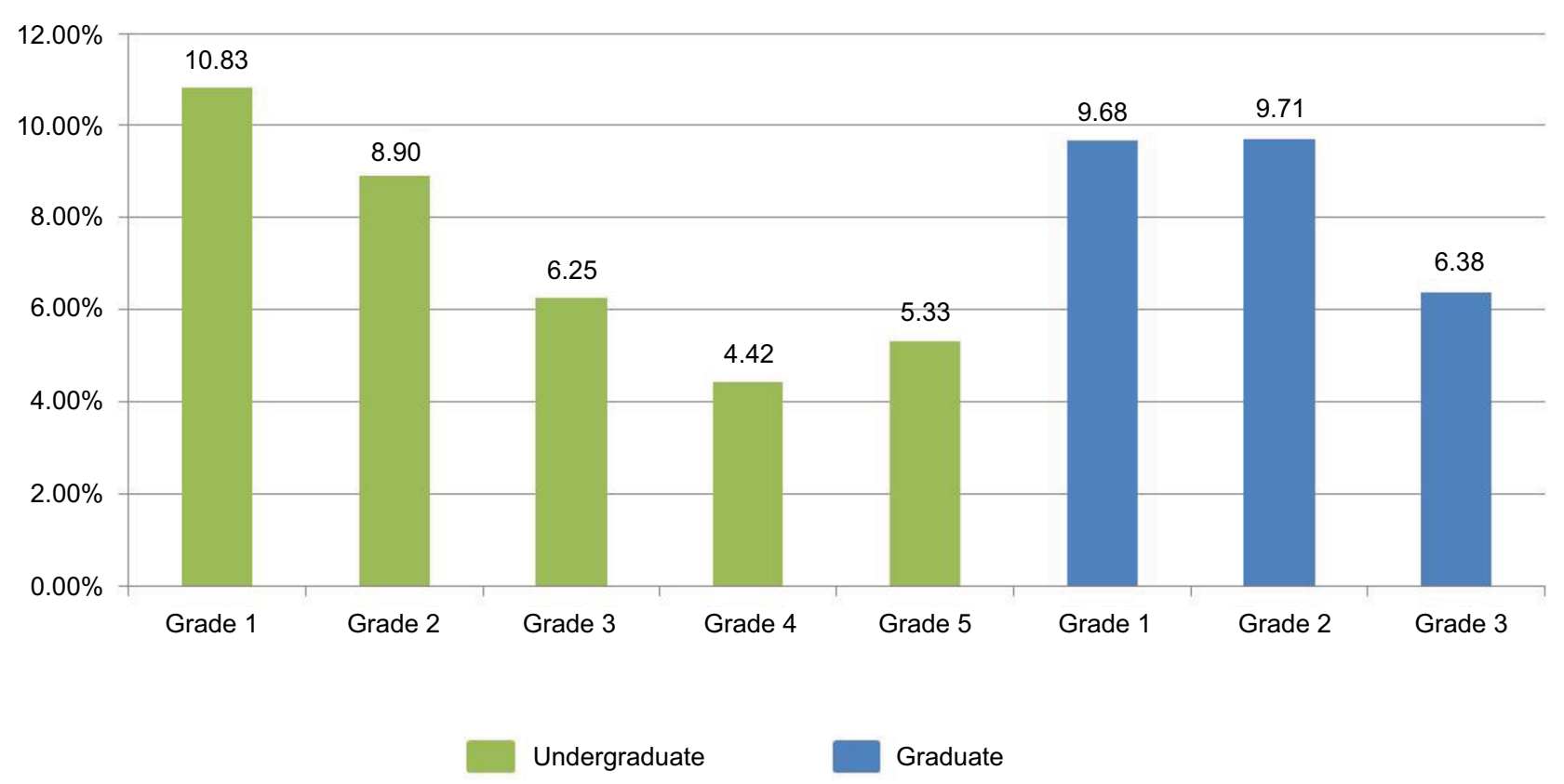

Figure I Prevalence of migraine in different grades.

Table 2 Prevalence of migraine according to participants' characteristics

\begin{tabular}{|c|c|c|c|c|}
\hline Characteristics & n (\%) & Prevalence (\%) & $95 \% \mathrm{Cl}(\%)$ & $P$ \\
\hline Overall & 986 & 7.91 & $6.23-9.60$ & \\
\hline Education level & & & & 0.594 \\
\hline Undergraduate & $696(70.59)$ & 7.61 & $5.64-9.59$ & \\
\hline Graduate & $290(29.4 I)$ & 8.62 & $5.39-11.85$ & \\
\hline Gender & & & & 0.004 \\
\hline Male & $366(37.12)$ & 4.64 & $2.48-6.80$ & \\
\hline Female & $620(62.88)$ & 9.84 & $7.5-12.18$ & \\
\hline Grade & & & & 0.181 \\
\hline Grade I & $250(25.35)$ & 10.40 & $2.55-8.12$ & \\
\hline Grade 2 & $294(29.82)$ & 9.18 & $2.07-6.78$ & \\
\hline Grade 3 & $254(25.76)$ & 6.30 & $3.31-9.29$ & \\
\hline Grade 4 & $113(11.46)$ & 4.42 & $3.86-|4.5|$ & \\
\hline Grade 5 & $75(7.61)$ & 5.33 & $3.49-\mid 7.31$ & \\
\hline Ethnicity & & & & 0.069 \\
\hline Han & $939(95.23)$ & 7.56 & $5.87-9.25$ & \\
\hline Minority & $47(4.77$ & 14.89 & $4.72-25.07$ & \\
\hline Birthplace & & & & 0.882 \\
\hline Rural & $523(53.04)$ & 8.00 & $5.67-10.33$ & \\
\hline Urban & $463(46.96)$ & 7.80 & $5.36-10.24$ & \\
\hline Living expenses/per month & & & & 0.019 \\
\hline$\leq ¥ 800$ & $127(12.88)$ & 14.17 & $8.10-20.24$ & \\
\hline$¥ 800-I, 200$ & $486(49.29)$ & 7.20 & $4.90-9.50$ & \\
\hline$\geq ¥ 1,200$ & $373(37.83)$ & 6.70 & $4.16-9.24$ & \\
\hline Family history of migraine & & & & $<0.001$ \\
\hline Yes & $87(8.82)$ & 22.99 & $14.15-3 \mid .83$ & \\
\hline No & $691(70.08)$ & 4.05 & $2.58-5.52$ & \\
\hline Unknown & $208(21.10)$ & 14.42 & $9.65-19.19$ & \\
\hline
\end{tabular}

Notes: $\mathrm{n}(\%)$ was the number and percentage for each variable among participants with migraine. P-values generated from Pearson Chi-square test or Fisher's exact test where appropriate. 
and family history of migraine were significantly associated with migraine in this study. Female students, students with lower living expenses, and those with a family history of migraine were highly likely to have migraine (all $P<0.05$ ). In the binary logistic regression analysis (Table 3), only gender (female, $\mathrm{OR}=2.24,95 \% \mathrm{CI}$ : 1.29-3.90) and family history of migraine (positive family history, $\mathrm{OR}=8.48,95 \%$ CI: 4.33-16.59) contributed significantly to migraine status.

\section{Features of migraine and migraineurs' attitude toward headache}

The features of migraine are shown in Table 4. More than half $(58.02 \%)$ of the migraineurs had migraine onset between the age of 15 and 20 years, two thirds $(66.67 \%)$ of the migraineurs reported irregular migraine attacks, and the majority experienced migraine attacks lasting $<24 \mathrm{~h}(94 \%)$. The median pain score for migraine attacks was 4 (IQR: 3-5) and ranged from 1-8. The intensity was categorized as mild (1-3), moderate (3-6), and severe $(\geq 7)$, and most students with migraine suffered mild $(44.9 \%)$ or moderate $(48.7 \%)$ pain. These migraine features did not significantly differ between male and female students.

Among 78 migraineurs, only $12 \%$ had visited a physician for their headache. Moreover, Figure 2 shows that rest or sleep was the most frequent method for relieving headaches. A quarter of the migraineurs had tried hot baths, drinking water, or eating. Non-medication methods were highly popular among migraineurs, and only eleven students reported trying self-medication, with five having used prescribed medication. Moreover, $8.6 \%, 21.1 \%$, and $60 \%$ of those with

Table 3 ORs of migraine cases according to characteristics using logistic regression analysis

\begin{tabular}{|c|c|c|c|c|}
\hline Characteristics & Crude OR $(95 \% \mathrm{Cl})^{a}$ & $P$ & Adjusted OR $(95 \% \mathrm{CI})^{\mathrm{b}}$ & $P$ \\
\hline \multicolumn{5}{|l|}{ Gender } \\
\hline Male & I & & I & \\
\hline Female & $2.24(1.287-3.898)$ & 0.004 & $2.529(1.317-4.856)$ & 0.005 \\
\hline \multicolumn{5}{|c|}{ Family history of migraine } \\
\hline Without & I & & I & \\
\hline With & $7.068(3.778-13.224)$ & 0.000 & $8.479(4.333-16.591)$ & 0.000 \\
\hline Unknown & 3.991 (2.323-6.855) & 0.000 & $4.328(2.395-7.820)$ & 0.000 \\
\hline \multicolumn{5}{|c|}{ Living expense/per month } \\
\hline$\leq ¥ 800$ & I & & I & \\
\hline$¥ 800-1,200$ & $0.47(0.256-0.86 I)$ & 0.015 & $0.545(0.282-1.053)$ & 0.071 \\
\hline$>¥ 1,200$ & $0.435(0.229-0.827)$ & 0.011 & $0.52(0.257-1.054)$ & 0.070 \\
\hline
\end{tabular}

Notes: ${ }^{a}$ Only the corresponding independent variable was entered into the model. ${ }^{\mathrm{b}}$ The regression model was adjusted for grade, age, body mass index, ethnicity, birthplace, and educational level.

Table 4 Features of migraine and differences between genders

\begin{tabular}{|c|c|c|c|c|}
\hline Characteristics & Total $n=78$ & Male $n=17$ & Female $n=61$ & $P$ \\
\hline \multicolumn{5}{|l|}{ Age at onset } \\
\hline$<15$ years & $13(16.67 \%)$ & 3 & 10 & \\
\hline $15-20$ years & 47 (60.25\%) & 13 & 34 & \\
\hline$>20$ years & $18(23.08 \%)$ & 1 & 17 & 0.154 \\
\hline \multicolumn{5}{|l|}{ Frequency } \\
\hline I-3 day/week & I (I.23\%) & 0 & 1 & \\
\hline 4-6 day/week & 9 (II.II\%) & 3 & 6 & \\
\hline Biweekly & $5(6.17 \%)$ & 1 & 4 & \\
\hline Monthly & 9 (II.II\%) & 1 & 8 & \\
\hline Irregular & $54(66.67 \%)$ & 12 & 42 & 0.817 \\
\hline \multicolumn{5}{|l|}{ Duration } \\
\hline$\geq 24 \mathrm{~h}$ & 5 (6.4I\%) & 1 & 4 & \\
\hline$>\mathrm{I} \mathrm{h}$ and $<24 \mathrm{~h}$ & 38 (48.72\%) & 6 & 32 & \\
\hline$\leq \mathrm{lh}$ & 35 (44.87\%) & 10 & 25 & 0.383 \\
\hline \multicolumn{5}{|l|}{ Intensity/median (IQR) } \\
\hline Visual Analog Scale & $4(3-5)$ & $3(3-4.5)$ & $3(4-5)$ & 0.689 \\
\hline
\end{tabular}

Notes: Values reported as mean (SD) or n (\%) for total sample, where appropriate. P-values generated from Mann-Whitney $U$ test, Person Chi-square test, or Fisher's exact test, wherever appropriate. 
mild, moderate, and severe headaches, respectively, used medication for pain relief. Apparently, more students who experienced severe pain took medication than those with milder pain $(P<0.05)$.

\section{Trigger factors}

The distribution and ranking of migraine triggers in our study are presented in Table 5. Stress at study or work (93.6\%) was the most reported trigger factor, followed by lack of sleep $(92.3 \%)$ and change in time of sleep (87.2\%). Almost three quarters of the migraineurs reported environmental triggers, including sudden change in temperature (79.5\%) and noise (76.9\%). Among the reported trigger factors, lack of sleep was the most frequent, and 59\% migraineurs considered it to have occurred "often or very often" before experiencing headache attacks. Other frequent trigger factors included

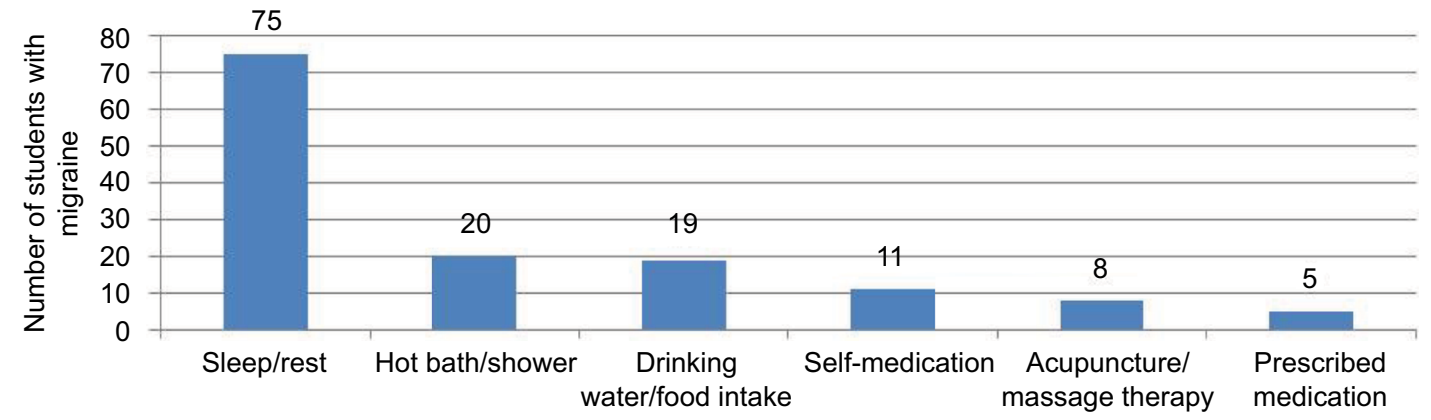

Figure 2 Coping strategies for migraine.

Table 5 Common and frequent trigger factors among medical students ${ }^{a}$

\begin{tabular}{|c|c|c|c|c|}
\hline Trigger factors & $\begin{array}{l}\text { n (\%) of migraineurs } \\
\text { considered it as a } \\
\text { trigger factor }^{b}\end{array}$ & Ranking & $\begin{array}{l}\text { n (\%) of migraineurs } \\
\text { considered it as a } \\
\text { frequent trigger factor }\end{array}$ & Rankinge \\
\hline Stress at study/work & 73 (93.59) & I & $36(46.15)$ & 2 \\
\hline Lack of sleep & $72(92.31)$ & 2 & $46(58.97)$ & I \\
\hline Changes in time of sleep & $68(87.18)$ & 3 & 34 (43.59) & 3 \\
\hline Sudden change in temperature & 62 (79.49) & 4 & $19(24.36)$ & 6 \\
\hline Noise & $60(76.92)$ & 5 & $20(25.64)$ & 5 \\
\hline Stress in personal life & $58(74.36)$ & 6 & $18(23.08)$ & 7 \\
\hline Smell & $57(73.08)$ & 7 & II (14.10) & 13 \\
\hline Menstrual cycle ${ }^{f}$ & $4 I(67.2 I)$ & 8 & $9(21.95)$ & 8 \\
\hline Stress - family & $49(62.82)$ & 9 & $15(19.23)$ & 11 \\
\hline Stress - sudden negative incidents & $48(61.54)$ & 10 & $16(20.51)$ & 10 \\
\hline Alcohol & $48(6 I .54)$ & 10 & $22(28.2 I)$ & 4 \\
\hline Seasonal change & $48(6 I .54)$ & 10 & 14 (I7.95) & 12 \\
\hline Oversleeping & $47(60.26)$ & 13 & II (14.10) & 13 \\
\hline Head and neck movement & $47(60.26)$ & 13 & II (14.10) & 13 \\
\hline Wind & $47(60.26)$ & 13 & II (14.10) & 13 \\
\hline Smoking & $46(58.97)$ & 16 & $17(2 \mid .79)$ & 9 \\
\hline Clarity & $44(56.41)$ & 17 & $4(5.13)$ & 20 \\
\hline Coffee & $36(46.54)$ & 18 & $8(10.26)$ & 17 \\
\hline Hunger & $35(44.87)$ & 19 & $3(3.85)$ & 22 \\
\hline Bingeing & $33(42.31)$ & 20 & 6 (7.69) & 18 \\
\hline Tea & $29(37.18)$ & 21 & $3(3.85)$ & 22 \\
\hline Milk and cheese & $26(33.33)$ & 22 & $6(7.69)$ & 18 \\
\hline Fasting & $24(30.77)$ & 23 & $\mathrm{I}(\mathrm{I} .28)$ & 25 \\
\hline Chocolate & $21(26.92)$ & 24 & $3(3.85)$ & 22 \\
\hline Other food & II (I4.10) & 25 & $4(5.13)$ & 20 \\
\hline
\end{tabular}

Notes: ${ }^{\mathrm{A}} \mathrm{A} 5$-point Likert scale was used to determine the most common and most frequent trigger factors. The 5-point Likert scale: $0=$ never, I=rarely/occasionally, $2=$ sometimes, $3=$ often, $4=$ very often. All the factors scored higher than " 0 " by the migraineurs were considered as a trigger factor in the study. The most common trigger factor meant most migraineurs selected it as a trigger factor. The most frequent trigger factor meant most migraineurs scored it higher than " 3 ". 'Percentage (\%) $=$ number of migraineurs selecting corresponding factor as a trigger/total number of migraineurs. ' Ranking of the most common trigger factor. ${ }^{\mathrm{C}}$ Percentage (\%) $=$ number of migraineurs selecting corresponding factor as a frequent trigger/number of migraineurs selecting corresponding factor as a trigger. ${ }^{\mathrm{e}}$ Ranking of the most frequent trigger factor. ${ }^{\mathrm{f}}$ Females only. 
stress at study or work (46.2\%) and changes in time of sleep (43.6\%). Additionally, drinking and smoking behaviors ranked high (fourth and ninth) among the frequent trigger factors in this study. Differences among common trigger factors between genders are shown in Figure 3. Alcohol was a frequent migraine trigger among male students but was significantly different among female students $(82.35 \%$ vs. $55.74 \%, P<0.05)$. Conversely, oversleeping was frequent among female students $(67.21 \%$ vs. $35.29 \%, P<0.05)$. Moreover, most (67.21\%) female migraineurs selected menstrual cycle as a migraine trigger, and it ranked eighth among the 25 trigger factors. These trigger factors were not significantly associated with the frequency, intensity, and duration of migraine attacks (all $P>0.05$ ).

\section{Discussion}

Our study found out that migraine was common among medical students in Soochow University and affected $7.9 \%$ of the population. The prevalence was significantly higher in female and junior-grade students and those with a family history of migraine. Most student migraineurs had migraine onset at ages between 15 and 20 and suffered mild, irregular, and short-term headache attacks. Moreover, the highly prevalent trigger factors were stress and lack of sleep. Seventy-eight of the 155 students who suffered headaches were screened using ID Migraine ${ }^{\mathrm{TM}}$, and based on previous sensitivity and specificity report, ${ }^{15}$ approximately $84 \%$ (66) of them were true positive. Besides, among those 908 students without migraine, approximately $76 \%$ (690) were true negative while others may have atypical migraine, or other kinds of primary or secondary headaches.

The overall migraine prevalence in our study was comparable to that in medical students in Northeast China $(7.91 \%$ vs. $8.6 \%)^{14}$ and to the general population of China $(9.3 \%){ }^{13}$ moreover, it is similar to the migraine prevalence among medical students in Iran $(7.14 \%, 7.3 \% \text {, and } 8.1 \%)^{23-25}$ and India $(8.6 \%) .{ }^{26}$ Furthermore, the overall migraine prevalence in our study is lower than that in students in the USA

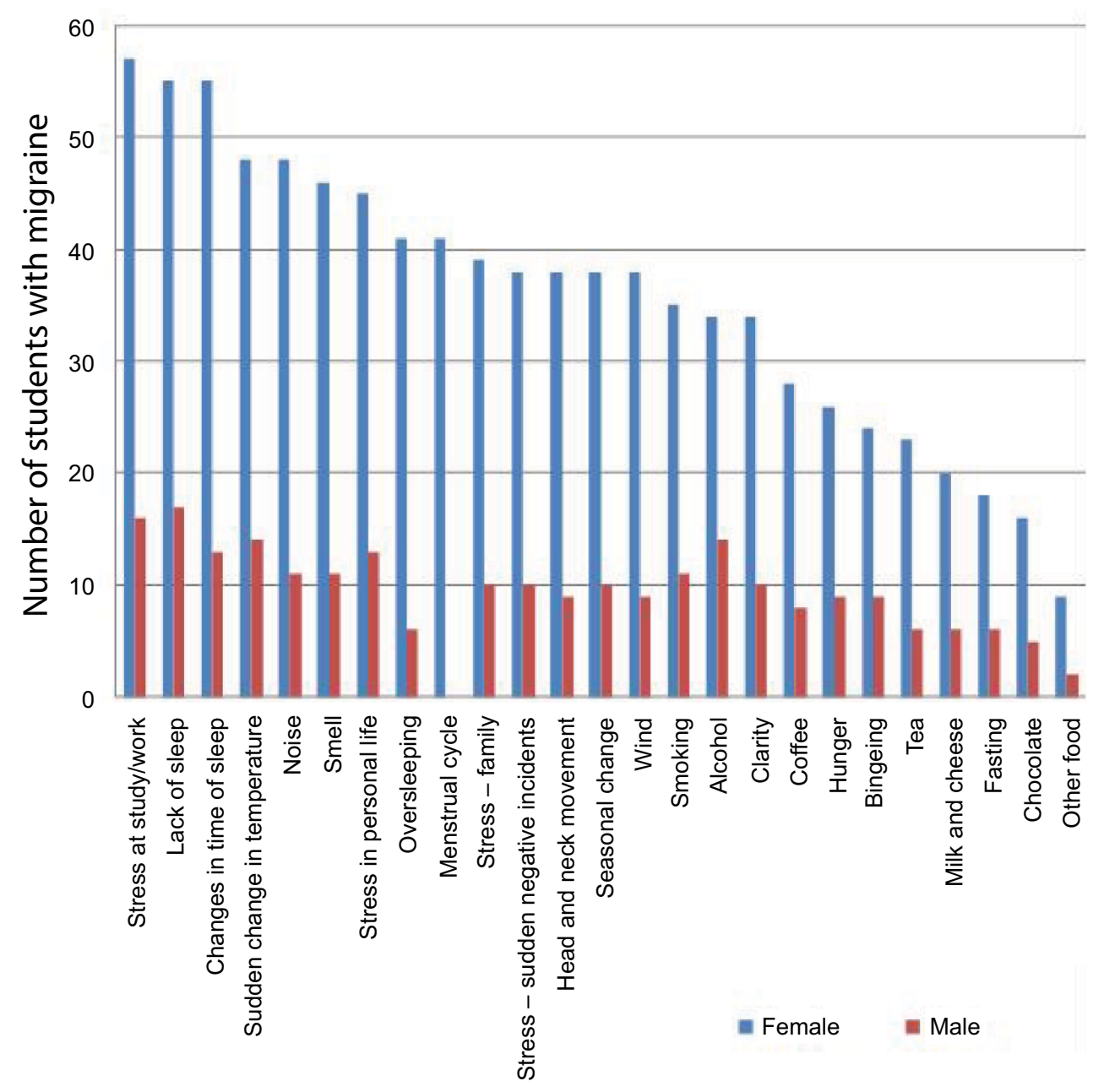

Figure 3 Trigger factors among male and female groups. 
$(24.8 \%)^{10}$ and Kuwait $(27.86 \%),{ }^{11}$ but higher than in Nigeria $(6.4 \%) .{ }^{27}$ Our results correspond with previous epidemiological studies, thereby proving that migraine is more prevalent in Europe and North America but less prevalent in Asia, Africa, and the Middle East. ${ }^{1}$

Most of the previous studies showed a higher prevalence among female than male students. ${ }^{10,11,26,27}$ One of the reasons might be the influence of estrogen, which causes menstrual migraine attacks to manifest without an aura and have increased duration, functional disability, and treatment resistance. ${ }^{28}$ However, some studies found no significant difference between male and female students. ${ }^{14,29}$ Ethnicity, diagnostic criteria, sampling method, and sample size might be the reasons that led to the discrepant results. In our study, nearly one quarter of the migraineurs, which is significantly higher than those without migraine, had a family history of migraine, pointing out the genetic predisposition of migraine. ${ }^{30}$

The present study showed a higher migraine prevalence among first and second year students in both undergraduate and graduate levels. This phenomenon may be explained by adaptive and learning pressures in a new environment among junior students in Soochow University. Previous studies showed inconsistent results regarding the relationship among migraine, age, and year of study. Some studies suggested that the migraine prevalence increased with age $\mathrm{e}^{14}$ and is high in the first and last two grades; ${ }^{11}$ however, other studies detected no significant relationship among these. ${ }^{25,27,31,32} \mathrm{We}$ speculate that these inconsistent results might be caused by the different time periods of survey during the academic year and the different medical educational systems.

According to univariate analysis, students with the lower living expense were more likely to suffer from migraine attacks; however, this association was eliminated in the multiple logistic regression analysis. Some studies suggested that in the general population, migraine prevalence increases as income decreases,$^{33}$ and teenagers from low-income households and without family history of migraine were more likely to suffer from migraine than children from higher-income families ${ }^{34}$ This showed that without the strong influence of genetic factors, personal or family economic status may contribute to migraine attacks due to financial stress or limited access to health care services.

Unlike studies conducted in the USA,${ }^{10}$ Kuwait, ${ }^{11}$ and South East Nigeria ${ }^{35}$ wherein the headaches were moderateto-severe, most students suffered from mild-to-moderate headaches in our study and in that from Northern India. ${ }^{26}$ Surprisingly, most of the students reported an irregular frequency of migraine attacks. The low level of migraine intensity, irregular episodes, and relatively short duration in both male and female students partly explained the low medication use and fewer clinical visits in our study.

Only $12 \%$ of the students suffering from migraine consulted a doctor specifically for headaches which was substantially lower than the $50 \%$ among migraine patients of the general population in the USA ${ }^{36}$ and China. ${ }^{37}$ Moreover, undiagnosed students, who were the majority in this study, showed other possibilities such as low awareness of migraine ${ }^{14}$ or inconvenient access to student health services.

Stress at work or study and lack of sleep were the most common $(91.25 \%, 90.0 \%)$ and frequent $(45 \%, 57.5 \%)$ trigger factors in our study. From a number of research results, $, 11,23,35$ stress and sleep problems were the two biggest sources of precipitating migraine attacks among medical students. All four aspects of stress listed in the questionnaire were ranked higher among overall triggers in our study; clearly, stress management is an important issue among medical students. Stress management programs should be developed so that students can learn the correct methods of stress alleviation. Moreover, personal habits and behaviors and environmental factors were found to trigger migraine attacks. To decrease the migraine attacks, reducing contact with these triggers is important. Furthermore, based on previous studies, menstrual migraine affects more than half of the female migraineurs. ${ }^{28}$ In our study, two thirds of female migraineurs considered menstrual cycle as a trigger for migraine attacks. Because menstrual cycle is unavoidable for women in the reproductive age, it is important to develop more effective treatment. ${ }^{38}$ Ranking of trigger factors was slightly different among female and male students, thereby suggesting that targeted prevention strategies for migraine attacks should be developed for male and female patients separately. Students would highly benefit from migraine prevention programs if these help them recognize trigger factors consciously and change behaviors or habits accordingly. Effective education for migraine awareness and pain relief should also be provided. Moreover, because triggers were also commonly found among patients with tension-type headache, ${ }^{7,20}$ further studies comparing these two kinds of primary headaches may help to enrich the content of headache-management programs.

\section{Strengths and limitations}

Our study provides evidence regarding associated trigger factors of migraine in Chinese university students that seems not to have been explored yet in this population. It provides 
evidence regarding associated trigger factors of migraine that has, to our best knowledge, never been explored in this population and indicates the need for migraine control programs to benefit student migraineurs. The school staff helped to enhance the students' trust and promote smooth progress of the study. Our questionnaire-based survey had a higher response rate of $96.2 \%$ than previous studies, ${ }^{10,11,14}$ indicating good compliance of responses in the students. However, this study still has some limitations. First, because we only screened the students who have had two or more headaches in the last 3 months, an underestimation of the migraine prevalence might have occurred. Moreover, some persons might only have one to two attacks within 1 year. Second, we did not identify the subtypes of migraine. Other than menstrual migraine, subtypes such as migraine with or without aura and episodic or chronic migraine, could not be clearly identified in our study, thereby limiting the insights into migraine features among different subtypes. Third, the nature of the cross-sectional study design presented students' recall bias to some extent. Fourth, this study only estimated the prevalence of migraine among medical students in one university, which made its representation limited to some extent. Moreover, stress is the only trigger factor in the emotional aspect in our study, which may not be comprehensive enough. Finally, our study did not discriminate between primary and secondary headaches. Further studies should focus on the general population as well as a specific study population that is vulnerable to migraine attacks and differentiate between primary and secondary headaches to gain more insight into the features and triggers of this disease.

\section{Conclusion}

Migraine is common among medical students in Soochow University and prevalent in female, junior students, and those with family history of migraine. Stress and lack of sleep are the most common trigger factors in this population. Future studies should focus on identifying migraine subtypes, as well as exploring details and information regarding trigger factors among medical students. Well-designed interventions for preventing migraine attacks and an educational program for increasing migraine awareness among medical students are also suggested.

\section{Acknowledgments}

YaShuang Zhao, MD, PhD, is thankfully acknowledged for the authorized use of the Chinese version of ID Migraine ${ }^{\mathrm{TM}}$. We wish to thank the Medical School of Soochow University, The First and Second Affiliated Hospital of Soochow University, and Suzhou Municipal Hospital for their support.

\section{Author contributions}

YJX and XG conceived and designed the study. XG did the data collection and statistical analysis and drafted the manuscript. YJX revised the manuscript. All authors contributed toward data analysis, drafting and revising the paper and agree to be accountable for all aspects of the work.

\section{Disclosure}

The authors report no conflicts of interest in this work.

\section{References}

1. Merikangas KR. Contributions of epidemiology to our understanding of migraine. Headache. 2013;53(2):230-246.

2. Vos T, Flaxman AD, Naghavi M, et al. Years lived with disability (YLDs) for 1160 sequelae of 289 diseases and injuries 1990-2010: a systematic analysis for the Global Burden of Disease Study 2010. Lancet. 2012;380(9859):2163-2196.

3. Steiner TJ, Stovner LJ, Birbeck GL. Migraine: the seventh disabler. $J$ Headache Pain. 2013;14(1):1.

4. Linde M, Gustavsson A, Stovner LJ, et al. The cost of headache disorders in Europe: the Eurolight project. Eur J Neurol. 2012;19(5):703-711.

5. Falavigna A, Teles AR, Velho MC, et al. Prevalence and impact of headache in undergraduate students in Southern Brazil. Arq Neuropsiquiatr. 2010;68(6):873-877.

6. Menon B, Kinnera N. Prevalence and characteristics of migraine in medical students and its impact on their daily activities. Ann Indian Acad Neurol. 2013;16(2):221-225.

7. Bigal ME, Bigal JM, Betti M, Bordini CA, Speciali JG. Evaluation of the impact of migraine and episodic tension-type headache on the quality of life and performance of a university student population. Headache. 2001;41(7):710-719.

8. Souza-e-Silva HR, Rocha-Filho PA. Headaches and academic performance in university students: a cross-sectional study. Headache. 2011;51(10):1493-1502.

9. Noor T, Sajjad A, Asma A. Frequency, character and predisposing factor of headache among students of medical college of Karachi. J Pak Med Assoc. 2016;66(2):159-164.

10. Johnson H, Guhl G, Arora J, Walling A. Migraine in students of a US medical school. Fam Med. 2014;46(8):615-619.

11. Al-Hashel JY, Ahmed SF, Alroughani R, Goadsby PJ. Migraine among medical students in Kuwait University. J Headache Pain. 2014;15:26.

12. Wang X, Zhou HB, Sun JM, Xing YH, Zhu YL, Zhao YS. The prevalence of migraine in university students: a systematic review and metaanalysis. Eur J Neurol. 2016;23(3):464-475.

13. Yu S, Liu R, Zhao G, et al. The prevalence and burden of primary headaches in China: a population-based door-to-door survey. Headache. 2012;52(4):582-591.

14. Wang X, Sun J, Xing Y, Zhou H, Zhao Y, Zhu Y. The prevalence and awareness of migraine among university students in Harbin, China. J Oral Facial Pain Headache. 2015;29(4):384-389.

15. Cousins G, Hijazze S, Van de Laar FA, Fahey T. Diagnostic accuracy of the ID Migraine: a systematic review and meta-analysis. Headache. 2011;51(7):1140-1148.

16. Domingues RB, Teixeira AL, Domingues SA. Physical practice is associated with less functional disability in medical students with migraine. Arq Neuropsiquiatr. 2011;69(1):39-43.

17. Balaban H, Semiz M, Şentürk IA, Kavakçı Ö, Cınar Z, Dikici A, Topaktaş $\mathrm{S}$. Migraine prevalence, alexithymia, and post-traumatic stress disorder among medical students in Turkey. J Headache Pain. 2012;13(6):459-467.

18. Wang X, San YZ, Sun JM, et al. Validation of the Chinese version of ID-Migraine in medical students and systematic review with meta-analysis concerning its diagnostic accuracy. J Oral Facial Pain Headache. 2015;29(3):265-278. 
19. Mollaoğlu M. Trigger factors in migraine patients. J Health Psychol. 2013;18(7):984-994.

20. Wang J, Huang Q, Li N, Tan G, Chen L, Zhou J. Triggers of migraine and tension-type headache in China: a clinic-based survey. Eur J Neurol. 2013;20(4):689-696.

21. Yu Y, Deng XZ, Zheng XX. [Study on the related factors of College Students' stress]. Journal of Wuhan Textile University. 2012;(5):46-48. Chinese.

22. Zhao XF, Ju LY, Rao CP, Wang XY, Zhang XY. [Food intake frequency and eating behavior among students in 5 colleges of Suzhou]. Chinese Journal of School Health. 2015;36(1):142-144. Chinese.

23. Shahrakai MR, Mirshekari H, Ghanbari AT, Shahraki AR, Shahraki E. Prevalence of migraine among medical students in Zahedan faculty of medicine (Southeast of Iran). Basic Clin Neurosci. 2011;2(2):20-25.

24. Hashemilar M, Amini SN, Savadi OD, Yosefian M. [The prevalence of migraine among students of Ardabil University of medical sciences]. Research \& Scientific Journal of Ardabil University of Medical Sciences \& Health Service. 2004;3(11). Arabic.

25. Farhad M, Rostam KM. Prevalence of tension and migraine headaches among the students of Ilam Medical University. Journal of Ilam University of Medical Sciences. 2008;15(4):13-21.

26. Nandha R, Chhabra MK. Prevalence and clinical characteristics of headache in dental students of a tertiary care teaching dental hospital in Northern India. International Journal of Basic \& Clinical Pharmacology. 2013;2(1).

27. Ojini FI, Okubadejo NU, Danesi MA. Prevalence and clinical characteristics of headache in medical students of the University of Lagos, Nigeria. Cephalalgia. 2009;29(4):472-477.

28. Brandes JL. The influence of estrogen on migraine: a systematic review. JAMA. 2006;295(15):1824-1830.
29. Khan A, Khattak H, Jamali R, Rashid H, Riaz A, Ibrahimzai AK. Prevalence of migraine, its common triggering factors and coping strategies in medical students of Peshawar. Khyber Medical University Journal. 2012;4(4).

30. Mulder EJ, Van Baal C, Gaist D, et al. Genetic and environmental influences on migraine: a twin study across six countries. Twin Res. 2003;6(5):422-431.

31. Yazdanparast M, Abrishamizadeh AA, Mahboobi H, et al. Prevalence of and factors associated with migraine in medical students at BandarAbbas, Southern Iran, in 2012. Electron Physician. 2013;5(3): 679-684.

32. Ghorbani A, Abtahi SM, Fereidan-Esfahani M, et al. Prevalence and clinical characteristics of headache among medical students, Isfahan, Iran. J Res Med Sci. 2013;18(Suppl 1):S24-27.

33. Stewart WF, Lipton RB, Celentano DD, Reed ML. Prevalence of migraine headache in the United States: relation to age, income, race, and other sociodemographic factors. JAMA. 1992;267(1):64-69.

34. Bigal ME, Lipton RB, Winner P, Reed ML, Diamond S, Stewart WF; AMPP advisory group. Migraine in adolescents: association with socioeconomic status and family history. Neurology. 2007;69(1):16-25.

35. Ezeala-Adikai BA, Ekenze OS, Onwuekwe IO. Frequency and pattern of migraine among medical and nursing students at Enugu, South East Nigeria. J Headache Pain. 2013;14(Suppl 1):P5.

36. Lipton RB, Bigal ME. Ten lessons on the epidemiology of migraine. Headache. 2007;47 Suppl 1:S2-9.

37. Yu S, Zhang M, Zhou J, Liu R, Wan Q, Li Y. Headache care in China. Headache. 2014;54(4):601-609.

38. Mathew PG, Dun EC, Luo JJ. A cyclic pain: the pathophysiology and treatment of menstrual migraine. Obstet Gynecol Surv. 2013;68(2):130-140.
Journal of Pain Research

\section{Publish your work in this journal}

The Journal of Pain Research is an international, peer reviewed, open access, online journal that welcomes laboratory and clinical findings in the fields of pain research and the prevention and management of pain. Original research, reviews, symposium reports, hypothesis formation and commentaries are all considered for publication.

\section{Dovepress}

The manuscript management system is completely online and includes a very quick and fair peer-review system, which is all easy to use. Visit http://www.dovepress.com/testimonials.php to read real quotes from published authors. 